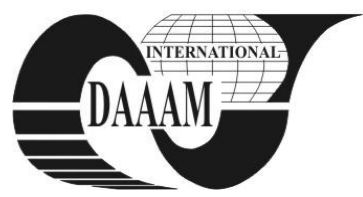

Annals of DAAAM for 2011 \& Proceedings of the 22nd International DAAAM Symposium, Volume 22, No. 1, ISSN 1726-9679 ISBN 978-3-901509-83-4, Editor B. Katalinic, Published by DAAAM International, Vienna, Austria, EU, 2011 Make Harmony between Technology and Nature, and Your Mind will Fly Free as a Bird Annals \& Proceedings of DAAAM International 2011

\title{
COMPARISON OF MATERIALS FRACTURE RESISTANCE BASED ON J-CRITERION
}

\author{
VUKELIC, G[oran] \& BRNIC, J[osip]
}

\begin{abstract}
The fracture behavior of compact type (CT) specimens made of two different materials, steel AISI 304 and AISI $316 L$ was numerically analyzed in this paper. The comparison of the two materials was based on the obtained values of J-integral, an important fracture mechanics parameter. The single specimen test method, commonly used in experimental determination of J-integral, was numerically modeled using finite element (FE) software. Consequently, a new numerical algorithm was developed for J-integral calculation on the basis of finite element (FE) analysis results. The paper sets out numerically obtained J-integral values presented as measure of crack driving force versus crack growth size ( $\triangle a$ a) for three initial measures of a specimen crack size, being $a / W=0.25,0.5,0.75$
\end{abstract}

Key words: fracture, AISI 304, AISI 316L, CT specimen, Jintegral, FE analysis

\section{INTRODUCTION}

Cracks usually appear in structures because of imperfections in design, manufacturing, service or maintenance. Since they can endanger the reliability and safety of both the structures and components, it is important to determine the modes in which they are manifested. This can be performed using fracture mechanics theories and parameters. $J$ integral is one of those parameters that is suitable for quantifying a crack driving force when a material ahead of a crack tip exhibits elastic-plastic behavior. Cracks growing from initial length $a$ could be of special interest when considering materials fracture resistance. For such cracks, $J$-integral values should be obtained for a number of crack extension values $(\Delta a)$. The results can be presented in $J-\Delta a$ sets of values, i.e. the variation of crack driving force during crack extension.

$J$-integral values for growing cracks can be measured by means of standardized experimental procedures. One of them is ASTM E1820 (ASTM, 2005.) that regulates the determination of $J$ values using single specimen test method on standardized specimens such as compact type specimen (CT). The single specimen test method follows elastic unloading compliance technique that uses measured crack mouth opening displacement to estimate the crack size. Collected values can be presented in terms of crack resistance curves.

Although $J$-integral values are usually obtained in a laboratory environment, this procedure can be performed using finite element (FE) method as a successful substitute for costly experiments. Numerous FE models have been developed for the simulation of the single specimen test method and for obtaining predicted crack resistance curves. Some of the previous researches include establishment of local ductile fracture criterion used in modeling of crack growth and $J-R$ curves simulation (Margolin \& Kostylev, 2001). FE models of singleedge notched tension specimens were developed for crack size evaluation using unloading compliance (Shen \& Tyson, 2009). $J$-integral method coupled with FE analysis was successfully used in computing stress intensity factor, an important fracture mechanics parameter in linear elastic material behavior (Tierean \& Baltes, 2009).
This paper aims at describing fracture behavior of two different types of steel. $J$-integral, as a fracture mechanics parameter, is obtained numerically using newly developed numerical algorithm based on FE analysis results. Resulting $J$ values are presented in correlation to crack growth $(\Delta a)$ and fracture behavior of two materials is compared.

\section{THEORETICAL BACKGROUND}

$J$-integral, a fracture mechanics parameter, was introduced as a path-independent integral which can be drawn around the tip of a crack and viewed both as an energy release rate parameter and a stress intensity parameter. In a twodimensional form it can be written as:

$$
J=\int_{\Gamma}\left(w d y-T_{i} \frac{\partial u_{i}}{\partial x} d s\right)
$$

where $W$ is strain energy density, $T_{i}=\sigma_{i j} n_{j}$ are components of the traction vector, $u_{i}$ are the displacement vector components and $d s$ is an incremental length along the contour $\Gamma$.

A numerical algorithm was developed in Matlab based on expression (1). First, FE model of cracked structure was defined. Stress analysis results from integration points in finite elements surrounding crack tip were used as input data for the algorithm. Evaluating $J$-integral values in these points and summing them along a path that encloses the crack tip, total value of $J$ is calculated. In each example, three different paths around crack tip were defined and their average value was taken as final since $J$-integral may differ in the vicinity of and away from the crack tip.

\section{MATERIAL DATA}

Two types of steels were examined in this research: a common grade stainless steel AISI 304 and AISI 316L, a low carbon grade of 316 commonly used in the fabrication of boilers and piping. Mechanical properties $\left(\sigma_{Y S}-\right.$ yield strength, $\sigma_{T S}$ - tensile strength) of materials are given in Tab. 1. (Brnic et al., 2010; Brnic et al., 2009].

\begin{tabular}{|c|c|c|}
\hline Material & $\sigma_{Y S}[\mathrm{MPa}]$ & $\sigma_{T S}[\mathrm{MPa}]$ \\
\hline AISI 304 & 540 & 734 \\
\hline AISI 316L & 467 & 600 \\
\hline
\end{tabular}

Tab. 1. Mechanical properties of examined materials

\section{FE MODEL}

The experimental single specimen test method following elastic unloading compliance technique was numerically simulated in order to determine $J$ values. This test method, defined by ASTM E1820, uses a measured crack mouth opening displacement to estimate growing crack size. The measured $J$ values can be presented in terms of variation of the crack driving force during the crack extension.

The fracture behavior of aforesaid materials was numerically examined using two-dimensional FE models of 
compact type (CT) specimens modeled in Ansys according to geometry given in [1], Fig. 3. The material behavior was considered to be of multilinear isotropic hardening type. Models of CT specimens were meshed with 8-node isoparamateric quadrilateral elements with particular care in discretization of the crack tip. A quasi-statical load was imposed on specimens to simulate the compliance procedure of the single specimen test method. Several initial crack sizes were modeled, $a / W$ (initial crack length/specimen width) $=0.25,0.5$, 0.75 . Crack propagation was simulated by means of the node releasing technique.

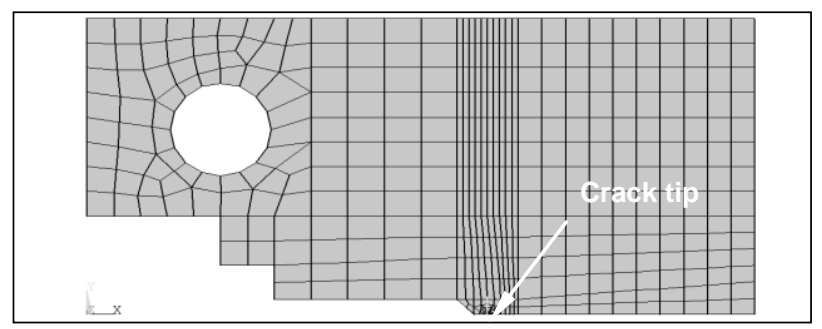

Fig. 1. FE model of a CT specimen

FE stress analysis results were recorded in integration points of the elements around crack tip for every crack extension size. These results were used as an input for developed numerical algorithm that calculates $J$ values along three paths that enclose the crack tip. Their average value represents the final value of $J$ for a specific crack size.

\section{RESULTS}

To verify the suitability of the procedure and numerical models, the resulting values of $J$-integral obtained on CT specimen made of AISI 304 with initial crack length of $a / W=$ 0.5 are compared with those obtained experimentally for same specimen made of similar material AISI 304LN (Roy et al., 2009), Fig. 2. A slight difference in $J$ values can probably be attributed to different compositions of AISI 304 and AISI 304LN. Good compatibility between experimental values of $J$ for a growing crack in CT specimen and numerically predicted values is noticeable. Such results gave confidence in further application of the $J$-integral evaluating method. Using suggested procedure $J$-integral values were calculated for growing cracks in CT specimens made of AISI 304 and AISI 316L for which experimental results were not available.

Numerically obtained $J$ values are presented as a measure of crack driving force versus crack growth size $(\Delta a)$, Fig. 2 and 3. Observing Fig. 2 and 3, it can be noted that AISI 304 steel has higher resulting values of $J$-integral than AISI $316 \mathrm{~L}$ steel. It is also noted that higher $a / W$ ratios correspond to lower $J$ integral values of the materials and vice versa.

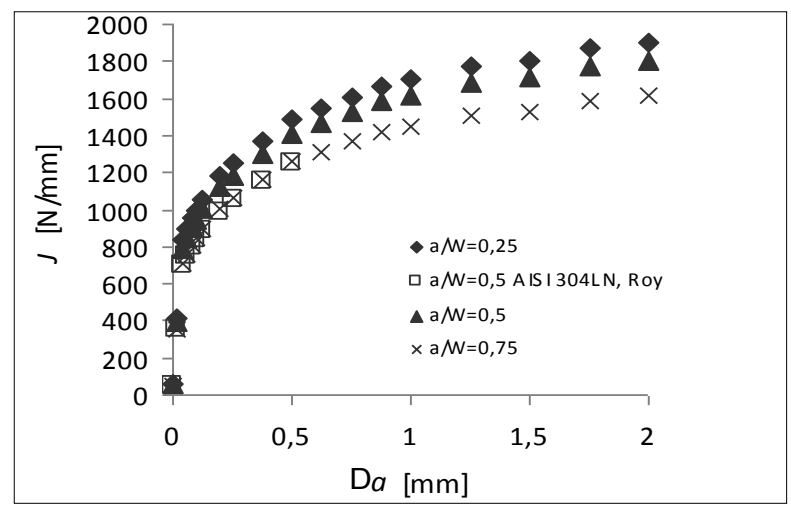

Fig. 2. AISI 304: predicted $J$ values for crack extension

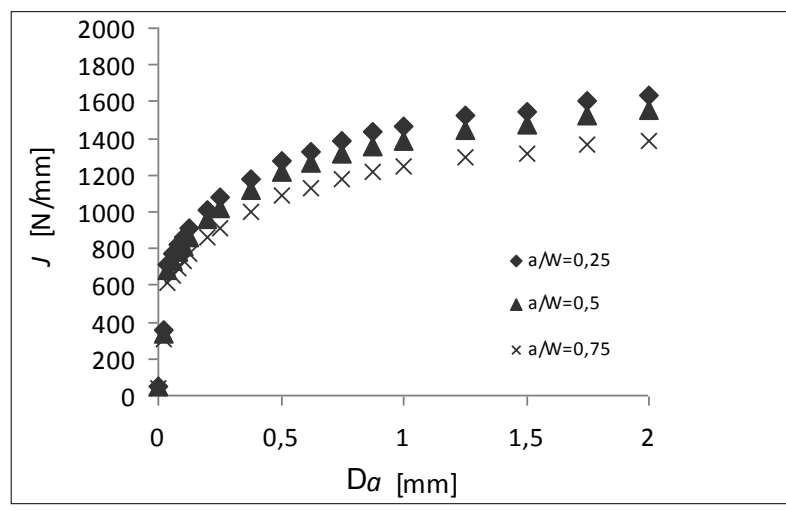

Fig. 3. AISI 316L: predicted $J$ values for crack extension $\Delta a$

\section{CONCLUSION}

Numerical algorithm, based on finite element stress analysis, was developed for $J$-integral calculation. $\mathrm{J}$ values obtained in such a way provide an insight into the values of the crack driving force for modeled CT specimens made of AISI 304 and AISI 316L containing a range of crack sizes. Results can be of a great help in the material selection process during the product design. Good compatibility of numerical and experimental results gives confidence in the use of algorithm for evaluating $J$ values of other materials. Extensive experimental procedures can be reduced when having numerical results as a starting point in the investigation of $J$ values for new materials. Developed algorithm is useful as an add-on for in-house built FE software without the capability of $J$-integral calculation. Further research can concentrate on applying the algorithm to different types of standardized specimens and materials, as well as to numerical models of real cracked structures and components.

\section{REFERENCES}

ASTM (2005.), Standard Test Method for Measurement of Fracture Toughness, E1820-01, ASTM, Baltimore

Brnic, J. et al. (2009). Behavior of AISI 316L Steel Subjected to Uniaxial State of Stress at Elevated Temperatures. Journal of Material Science and Technology, 25, 2, (2009) 175-180, ISSN 1005-0302

Brnic, J. et al. (2010). Experimental Determination of Mechanical Properties and Short-Time Creep of AISI 304 Steel at Elevated Temperatures. International Journal of Minerals, Metallurgy and Materials, 17, 1 (2010) 39-45, ISSN 1674-4799

Margolin, B.Z. et al. (2001). Simulation of J-R curves for reactor pressure vessels steels on the basis of a ductile fracture model. International Journal of Pressure Vessels and Piping, 78, (2001) 715-725, ISSN 0308-0161

Roy, H. et al. (2009). Monotonic Vis-à-Vis Cyclic Fracture Behavior of AISI 304LN Stainless Steel. Engineering Fracture Mechanics, 76, (2009) 1822-1832, ISSN 00137944

Shen, G. \& Tyson, W.R. (2009) Crack Size Evaluation Using Unloading Compliance in Single-Specimen Single-EdgeNotched Tension Fracture Toughness Testing. Journal of Testing and Evaluation, 37, 4 (2009) 347-357, ISSN 00903973

Tierean, M. \& Baltes, L. (2009). Computing of Stress Intensity Factor Using J-Integral Method with F.E.A., Annals of DAAAM 2009 \& Proceedings of the 20th Int. DAAAM Symposium, 25-28.11.2009, Vienna, Austria, ISSN 17269679, ISBN 978-3-901509-70-4, Katalinic, B. (Ed.), 11051106, DAAAM Int., Vienna 